University of Nebraska - Lincoln

DigitalCommons@University of Nebraska - Lincoln

2012

\title{
Incidence of Laryngospasm and Bronchospasm in Pediatric Adenotonsillectomy
}

\author{
Michael I. Orestes \\ Walter Reed Army Medical Center \\ Lina Lander \\ University of Nebraska Medical Center, Ilander@unmc.edu \\ Susan Verghese \\ Children's National Medical Center \\ Rahul K. Shah \\ Children's National Medical Center, rshah@childrensnational.org
}

Follow this and additional works at: https://digitalcommons.unl.edu/usarmyresearch

Orestes, Michael I.; Lander, Lina; Verghese, Susan; and Shah, Rahul K., "Incidence of Laryngospasm and Bronchospasm in Pediatric Adenotonsillectomy" (2012). US Army Research. 257.

https://digitalcommons.unl.edu/usarmyresearch/257

This Article is brought to you for free and open access by the U.S. Department of Defense at DigitalCommons@University of Nebraska - Lincoln. It has been accepted for inclusion in US Army Research by an authorized administrator of DigitalCommons@University of Nebraska - Lincoln. 


\title{
Incidence of Laryngospasm and Bronchospasm in Pediatric Adenotonsillectomy
}

\author{
Michael I. Orestes, MD; Lina Lander, ScD; Susan Verghese, MD; Rahul K. Shah, MD
}

\begin{abstract}
Objectives/Hypothesis: To evaluate and describe airway complications in pediatric adenotonsillectomy.
Study Design: Retrospective case-control study.

Methods: A chart review of patients that underwent adenotonsillectomy between 2006 and 2010 was performed. Perioperative complications, patient characteristics, and surgeon and anesthesia technique were recorded.

Results: A total of 682 charts were reviewed. Eleven cases (1.6\%) of laryngospasm were identified: one was preoperative, seven occurred in the operating room postextubation, and three occurred in the recovery area. Four patients were given succinylcholine, one was reintubated, and the other cases were managed conservatively. Mean age of patients with laryngospasm was 5.87 years (standard deviation [SD], 4.01; 1.9-15.8 years). There were 12 cases (1.8\%) of bronchospasm; all were treated with nebulized albuterol. Mean age of patients with bronchospasm was 5.81 years (SD, 4.17; 1.8-14.1 years). Overall, 22 patients required antiemetics (3.3\%), 19 required albuterol (2.9\%), and five required racemic epinephrine (0.8\%). Compared to the children without airway complications, there was no difference in age, weight, American Society of Anesthesiologists status, length of surgery, need for admission, and anesthesia technique in those that had laryngospasm. Patients with bronchospasm, compared to the patients without complications, had faster surgeries $(P<.05)$, were more likely to have underlying asthma $(P<.05)$, and were more likely to be admitted $(P<.05)$. There were no unexpected admissions or other morbidities.

Conclusions: The rates of laryngospasm (1.6\%) and bronchospasm (1.8\%) are significantly lower than reported in the literature, reflecting refinements in modern anesthesia/surgical technique. Knowledge of at-risk patients can facilitate planning to potentially reduce the incidence of perioperative airway complications during adenotonsillectomy.

Key Words: Tonsillectomy, adenoidectomy, outcomes, laryngospasm, bronchospasm.

Level of Evidence: $2 b$.

Laryngoscope, 122:425-428, 2012
\end{abstract}

\section{INTRODUCTION}

Pediatric adenotonsillectomy remains one of the most common surgical procedures in the United States. ${ }^{1}$ In the past few decades, there have been significant advances in the surgical technique, anesthetic approaches, and recovery and postoperative management of these patients. As a result, the outcomes and resultant morbidity have significantly improved. ${ }^{2}$ One of the most feared complications of pediatric adenotonsillectomy is airway complications. ${ }^{3,4}$ These complications can occur during adenotonsillectomy or in the perioperative period and may include laryngospasm and bronchospasm and result in significant morbidity and

From the National Capitol Consortium Otolaryngology Residency Training Program (M.I.o.), Walter Reed Army Medical Center, Washington, DC; Department of Epidemiology, University of Nebraska Medical Center (L.L.), Omaha, Nebraska, Division of Anesthesiology (s.v.), Division of Otolaryngology (R.K.s.), Children's National Medical Center, Washington, DC, U.S.A. $21,2011$.

Editor's Note: This Manuscript was accepted for publication July

Delivered in part as an oral presentation at the Annual Meeting of the Triological Society, Chicago, Illinois, U.S.A., April 28, 2011.

The authors have no funding, financial relationships, or conflicts of interest to disclose.

Send correspondence to Rahul K. Shah, MD, Division of Otolaryngology, Children's National Medical Center, 111 Michigan Avenue NW, Washington, DC 20010. E-mail: rshah@childrensnational.org

DOI: 10.1002/lary.22423 prolonged hospitalization for the patient. ${ }^{5,6}$ Such complications require intense, rapid response from the anesthesia and surgical team as well as comprehensive postoperative monitoring around the time of the event.

As outcomes have improved for pediatric adenotonsillectomy, the surgery is now performed more frequently in higher-risk populations such as younger children and children with syndromes and craniofacial abnormalities. ${ }^{4,7}$

Despite the frequency of this surgery, the incidence and significance of perioperative airway complications in this cohort of patients has not recently been studied. Indeed, the historic citations of the rates of laryngospasm and bronchospasm for adenotonsillectomy have not been recently updated. ${ }^{8,9}$ With advanced surgical techniques and refined anesthetic approaches with faster-acting anesthetic agents resulting in faster recovery times, the role that airway complications play in the overall outcomes of these patients is significant.

The objective of this study is to evaluate a single surgeon's experience at a tertiary care academic medical center to obtain a current rate of airway complications during the perioperative period for adenotonsillectomy as well as determine the outcomes and management of these patients with the anticipation that identification of high-risk patients for such complications will allow surgery in these patients to be tailored as needed. 


\section{MATERIALS AND METHODS}

Institutional review board approval from Children's National Medical Center was obtained. Patients that underwent adenotonsillectomy by the senior author (R.K.S.) were enrolled in the study. In an attempt to control for as many variables as possible, it was deemed appropriate to use data from only one surgeon, as it enabled comparison of myriad variables without the confounding variable of different surgeons. We included patients who underwent an adenotonsillectomy between August 2006 and December 2010 at either the main campus operating room or the ambulatory surgery center at Children's National Medical Center.

Each patient's chart was reviewed in totality to extract pertinent information such as patient characteristics (demographics and complications) including the American Society of Anesthesiologists (ASA) Physical Status classification, perioperative data (length of surgery, time of recovery, disposition status), intraoperative data (medications administered, oxygen saturation characteristics), and postoperative outcomes and complications. For all cases with airway complications, the senior authors (s.v., R.K.s.) reviewed each chart in detail.

For bronchospasm, the authors erred on the side of caution in classifying a case as such-for example, if the patient received albuterol, the patient was considered to have increased airway reactivity and hence we classified this patient as having bronchospasm. Because this was a retrospective review, it was nearly impossible to know for sure whether intraoperative bronchospasm actually occurred. Hence, administration of albuterol was used as a surrogate marker for such. Comorbid conditions for the patients were recorded and included asthma, gastroesophageal reflux disease, sickle cell, trisomy 21 , and failure to thrive.

Statistical analysis was performed to calculate significance for these variables for the respective airway complications.

\section{RESULTS}

A total of 682 charts were reviewed ( $54 \%$ male); patient ages ranged from 0.7 to 19.3 years, and patients underwent adenotonsillectomy with a mean duration of surgery of 19.6 minutes in those patients without airway complications (Table I). The average weight of the patients in the noncomplication group was $34.4 \mathrm{~kg}$. Patients were classified as follows: $34 \%$ were ASA 1 , $61 \%$ were ASA 2 , and $5 \%$ were ASA 3 .

Eleven cases $(1.6 \%)$ of laryngospasm were identified: one was following anesthetic induction before surgery, seven occurred in the operating room postextubation, and three occurred in the recovery area. Four were given succinylcholine, one was reintubated, and the other cases were managed conservatively. Mean age of patients with laryngospasm was 5.87 years (standard deviation [SD], 4.01; 1.9-15.8 years). There were 12 cases $(1.8 \%)$ of bronchospasm or increased airway resistance; all were treated with nebulized albuterol using a metered-dose inhaler. Mean age of patients with bronchospasm was 5.81 years (SD, 4.17; 1.8-14.1 years). Overall, 22 patients required additional antiemetics $(3.3 \%), 19$ needed albuterol $(2.9 \%)$, and five required racemic epinephrine $(0.8 \%)$.

Table I lists each variable studied and the incidence and significance with regard to those patients at risk for laryngospasm and bronchospasm. Compared to the children without airway complications, those that had laryngospasm showed no difference in age, weight, ASA status, length of surgery, need for admission, and anesthesia technique. Patients with bronchospasm, compared to the patients without complications, had faster surgeries $(P<.05)$, were more likely to have asthma $(P<$ $.05)$, and were more likely to be admitted $(P<.05)$. There were no other morbidities and no mortalities in the patients reviewed.

\section{DISCUSSION}

Pediatric adenotonsillectomy is one of the most common surgeries performed in the United States. ${ }^{1}$ There have been significant advances in the surgical technique, anesthesia technique, and characteristics of patients undergoing surgery in the past decades. This is juxtaposed by external forces to shorten the length of stay of patients and perhaps to minimize the need for patients to remain in a monitored setting. ${ }^{4}$ A recent, robust, prospective study outlined risk factors for a child undergoing pediatric anesthesia. ${ }^{10}$ Some of these included a positive respiratory history, upper respiratory tract infection when symptoms were present 2 weeks before the procedure, and a history of at least two family members having asthma, atopy, or smoking. ${ }^{10}$ In our recent anecdotal experience, we have noted a significant decrease in the rate of perioperative airway complications in pediatric adenotonsillectomy. However, a literature review demonstrates that there have not been recent studies supporting this sentiment. As such, the present study was conducted to examine this hypothesis.

In our study population, an inner city, tertiary-care, free-standing, academic medical center with fellowship trained pediatric otolaryngologists and fellowship-trained pediatric anesthesiologists, the rate of laryngospasm and bronchospasm in pediatric adenotonsillectomy was $1.6 \%$ and $1.8 \%$. Historically, and in other institutions, the rate of laryngospasm and bronchospasm has been noted to be significantly higher. A recent study comparing laryngeal mask airway to endotracheal tube intubation for managing the airway in pediatric adenotonsillectomy identified rates of laryngospasm of $12.5 \%$ in the laryngeal mask airway cohort and $9.6 \%$ in the intubated patients; this is higher than our rate by almost an order of magnitude. ${ }^{11}$ Their findings are supported by other studies with a rate of about $8 \%$ in a large study conducted over 4 years with more than 1,000 patients. ${ }^{6}$ A study from 2 decades prior noted that the use of topical lidocaine reduced the rate of laryngospasm from $12 \%$ to $3 \% .^{8}$ Similarly, a comparison of anesthesia techniques found that using propofol reduced the rate of laryngospasm from $20 \%$ to $6.6 \%$; however, the sample size in that study was quite small. ${ }^{5}$ Patient characteristics can, of course, affect the rate of airway complications as noted in the study by Mitchell and Kelly, as almost one-quarter of the young children in the group undergoing surgery had postoperative complications including laryngospasm and marked desaturations. ${ }^{12}$

Interestingly, in the general pediatric population that undergoes surgery, the risk of laryngospasm has been shown to be increased in children with upper respiratory tract infection, a preexisting airway anomaly, or 
TABLE I.

Pertinent Variables and Characteristics of Patients Who Had a Perioperative Airway Complication During an Adenotonsillectomy ( $\mathrm{N}=682$ ).

\begin{tabular}{|c|c|c|c|c|c|}
\hline Variable & $\begin{array}{l}\text { Patients Without } \\
\text { Complications }\end{array}$ & $\begin{array}{l}\text { Patients With } \\
\text { Laryngospasm }\end{array}$ & $P$ Value & $\begin{array}{l}\text { Patients With } \\
\text { Bronchospasm }\end{array}$ & $P$ Value \\
\hline No. of patients & 659 & 11 & & 12 & \\
\hline Sex, female, no. (\%) & $306(46)$ & $6(55)$ & .5927 & $4(33)$ & .4002 \\
\hline Age, mean (SD) & $7.28(4.04)$ & $5.87(4.01)$ & .2504 & $5.81(4.17)$ & .2105 \\
\hline Weight, kg, mean (SD) & $34.43(25.02)$ & $27.52(16.89)$ & .3618 & $26.09(19.16)$ & .2513 \\
\hline Length of surgery, min, mean (SD) & $19.64(11.50)$ & $24.27(15.89)$ & .1891 & $15.17(5.57)$ & .0192 \\
\hline $\begin{array}{l}\text { Preoperative oxygenation level, } \\
\text { oxygen saturation (SD) }\end{array}$ & $98.98(4.53)$ & $99.0(1.55)$ & .9723 & $98.36(3.59)$ & .6531 \\
\hline $\begin{array}{l}\text { Postoperative oxygenation level, } \\
\text { oxygen saturation (SD) }\end{array}$ & $98.43(4.15)$ & $98.82(1.54)$ & .4419 & $98.83(1.47)$ & .3863 \\
\hline ASA status, no. & 657 & 11 & .2796 & & .3092 \\
\hline 1 & 227 & 2 & & 2 & \\
\hline 2 & 397 & 8 & & 9 & \\
\hline 3 & 33 & 1 & & 1 & \\
\hline \multicolumn{6}{|l|}{ Comorbidity, no. } \\
\hline Asthma & 177 & 3 & .9999 & 10 & $<.0001$ \\
\hline GERD & 20 & 1 & .2974 & 2 & .0555 \\
\hline Down syndrome & 12 & 0 & .9999 & 1 & .2108 \\
\hline Sickle-cell disease & 6 & 0 & .9999 & 0 & .9999 \\
\hline Failure to thrive & 21 & 0 & .9999 & 0 & .9999 \\
\hline \multicolumn{6}{|l|}{ Intraoperative medications, no. } \\
\hline Propofol & 533 & 10 & .6995 & 10 & .9999 \\
\hline Dexmedetomidine & 17 & 1 & .2609 & 0 & .9999 \\
\hline Sevoflurane & 641 & 11 & .9999 & 12 & .9999 \\
\hline Desflurane & 445 & 6 & .3514 & 5 & .0687 \\
\hline Nitrous oxide & 635 & 11 & .9999 & 11 & .3684 \\
\hline Decadron & 641 & 10 & .2370 & 11 & .2936 \\
\hline Antiemetic & 626 & 10 & .4386 & 11 & .4670 \\
\hline \multicolumn{6}{|c|}{ Postoperative complications and management, no. } \\
\hline Emesis & 46 & 1 & .5541 & 1 & .5853 \\
\hline Immediate bleed & 3 & 0 & .9999 & 0 & .9999 \\
\hline Reintubation & 3 & 1 & .0642 & 0 & .9999 \\
\hline Succinylcholine & 0 & 3 & $<.0001$ & 0 & .9999 \\
\hline Albuterol & 19 & 1 & .2853 & 10 & $<.0001$ \\
\hline Racemic epinephrine & 5 & 0 & .9999 & 1 & .1031 \\
\hline CXR & 6 & 0 & .9999 & 2 & .0077 \\
\hline Antiemetics & 22 & 0 & .9999 & 1 & .3443 \\
\hline Admitted & 23 & 0 & .9999 & 5 & $<.0001$ \\
\hline
\end{tabular}

$\mathrm{SD}=$ standard deviation; ASA = American Society of Anesthesiologists; GERD = gastroesophageal reflux disease; CXR = chest radiograph.

when a laryngeal mask airway was utilized. ${ }^{13}$ A rate of bronchospasm of $1.5 \%$ in healthy children was reported in a study comparing healthy children with those with respiratory tract infections. Children with such infections were able to have the rate of bronchospasm and coughing reduced by use of a $\beta-2$ agonist. ${ }^{14}$ These authors showed that children at high risk for perioperative adverse events could be assessed preoperatively by using highly specific and selective questions at the telephone screening. ${ }^{14}$ This early screening can help triage specific perioperative prophylactic therapy as well as tailor the specific anesthetic to potentially decrease these respiratory complications. Early effective communication between the pediatrician, pulmonologist (as needed), otolaryngologist, preoperative screening nurse, parents, anesthesiologist, and the postanesthesia care unit nurse is critical in assessing the risks and maximizing therapy in the perioperative period.

The low incidence of bronchospasm in our review may be the result of our institutional policies regarding preoperative assessment and preparation of asthmatic patients. When the otolaryngologist encounters a brittle asthmatic patient who requires surgery, he or she usually sends that patient for pulmonary and anesthesia 
consults to alert them about the impending surgery and the need for maximizing antiasthmatic therapy. In addition, parents are instructed to give the patient a nebulizer treatment on the night before surgery and the morning of surgery as well as to be highly aware of the need to contact the preoperative team should the patient develop upper respiratory infection just before the planned surgery. Furthermore, additional nebulized albuterol is frequently given during surgery especially just before extubation.

Our study does not resolve the controversy regarding the incidence of perioperative airway complications; however, with our large sample size and detailed review of the anesthesia record, we believe that our conclusions regarding the refinement in anesthesia and surgical techniques resulting in this marked decrease in perioperative airway complications will be corroborated by similar studies in the coming years.

As the rate of perioperative airway complications has been reduced significantly, there is an onus to better define those patients that are at risk for such. Compared to the children without airway complications, those that had laryngospasm showed no difference in age, weight, ASA status, length of surgery, need for admission, and anesthesia technique. As expected, the majority of patients with laryngospasm $(63 \%)$ were in the postoperative period in the periextubation period. Interestingly, there exists the belief and the studies to indicate that patients with laryngospasm are younger. ${ }^{12}$ Our data demonstrate that the patients with laryngospasm were not very young, as their mean age was a little less than 6 years. The value of such knowledge is that the anesthesiologist may consider all children to be at high risk for laryngospasm because it occurs so infrequently with modern anesthesia techniques.

Patients with bronchospasm, compared to the patients without complications, had faster surgeries $(P$ $<.05)$, were more likely to have asthma $(P<.05)$, and were more likely to be admitted $(P<.05)$. The latter two variables are intuitive in that a reactive airway or increased airway resistance (as noted by the underlying asthma) certainly precludes the child to having bronchospasm. Furthermore, a reactive airway takes time to stabilize and placate, and as such, these patients should be and were admitted in our study. Knowledge of the strong association between pediatric adenotonsillectomy, asthma, and the resultant admission should suggest to anesthesiologists that patients with underlying asthma be aggressively optimized before surgery to minimize such risk and avert a possible complication and admission.

Despite the low prevalence and quite significant decrease in perioperative airway complications in the past decades, the question emerges: Who are the children most affected and how can this risk be appropriately mitigated? This study is an initial foray into answering such question. In an effort to reduce laryngospasm, attention should be focused on the intraoperative period, particularly the periextubation period, with the knowledge that these patients may need to be reintubated; however, this will usually not result in an admission. For bronchospasm, significant effort, including perhaps formal pulmonary evaluation of severe asthmatics before surgery, should be focused on clarifying and optimizing the patient's history of asthma as well as including a preoperative asthma plan. One may consider that this be done on a national level to standardize preoperative preparation of children for adenotonsillectomy in the setting of asthma. Not only will such interventions be of benefit to the patient, but also the health-care system will avoid a costly, potentially preventable admission.

\section{CONCLUSION}

The rates of laryngospasm (1.6\%) and bronchospasm (1.8\%) reported here are lower than those reported in the literature, reflecting modern refinements in anesthesia and surgical technique. Knowledge of patients vulnerable to these complications allows for optimal anesthesia technique in high-risk patients and may potentially further reduce the incidence of perioperative airway complications during adenotonsillectomy.

\section{BIBLIOGRAPHY}

1. Baugh RF, Archer SM, Mitchell RB, et al. Clinical practice guideline: tonsillectomy in children. Otolaryngol Head Neck Surg 2011;144:S1-S30.

2. Jaryszak EM, Lander L, Patel AK, Choi SS, Shah RK. Prolonged recovery after out-patient pediatric adenotonsillectomy. Int J Pediatr Otorhinolaryngol 2011;75:585-588.

3. Jaryszak EM, Shah RK, Vanison CC, Lander L, Choi SS. Polysomnographic variables predictive of adverse respiratory events after pediatric adenotonsillectomy. Arch Otolaryngol Head Neck Surg 2011;137:15-18.

4. Shah RK, Welborn L, Ashktorab S, Stringer E, Zalzal GH. Safety and outcomes of outpatient pediatric otolaryngology procedures at an ambulatory surgery center. Laryngoscope 2008;118:1937-1940.

5. Batra YK, Ivanova M, Ali SS, Shamsah M, Al Qattan AR, Belani KG. The efficacy of a subhypnotic dose of propofol in preventing laryngospasm following tonsillectomy and adenoidectomy in children. Paediatr Anaesth 2005;15:1094-1097.

6. Al-Metwalli RR, Mowafi HA, Ismail SA. Gentle chest compression relieves extubation laryngospasm in children. $J$ Anesth 2010;24:854-857.

7. Merrell JA, Shott SR. OSAS in Down syndrome: T\&A versus T\&A plus lateral pharyngoplasty. Int J Pediatr Otorhinolaryngol 2007;71:1197-1203.

8. Staffel JG, Weissler MC, Tyler EP, Drake AF. The prevention of postoperative stridor and laryngospasm with topical lidocaine. Arch Otolaryngol Head Neck Surg 1991;117:1123-1128.

9. Patel RI, Hannallah RS, Norden J, Casey WF, Verghese ST. Emergence airway complications in children: a comparison of tracheal extubation in awake and deeply anesthetized patients. Anesth Analg 1991;73:266-270.

10. von Ungern-Sternberg BS, Boda K, Chambers NA, et al. Risk assessment for respiratory complications in paediatric anaesthesia: a prospective cohort study. Lancet 2010;376:773-783.

11. Peng A, Dodson KM, Thacker LR, Kierce J, Shapiro J, Baldassari CM. Use of laryngeal mask airway in pediatric adenotonsillectomy. Arch Otolaryngol Head Neck Surg 2011:137:42-46.

12. Mitchell RB, Kelly J. Outcome of adenotonsillectomy for obstructive sleep apnea in children under 3 years. Otolaryngol Head Neck Surg 2005;132: 681-684.

13. Flick RP, Wilder RT, Pieper SF, et al. Risk factors for laryngospasm in children during general anesthesia. Paediatr Anaesth 2008;18:289-296.

14. von Ungern-Sternberg BS, Habre W, Erb TO, Heaney M. Salbutamol premedication in children with a recent respiratory tract infection. Paediatr Anaesth 2009;19:1064-1069. 